\title{
Perkembangan pelaksanaan Audit di Era teknologi informasi
}

\author{
Mayang Sunesti \\ 175100023 \\ Fakultas Komputer \\ mayangsunesti.student@umitra.ac.id
}

\begin{abstract}
Abstrak
Ditinjau dari definisinya, informasi adalah suatu data yang sudah diolah sehingga menghasilkan sesuatu yang berguna bagi pemakainya. Menurut Wilkinson, dalam pengertian yang luas, informasi adalah intelegensi yang mempunyai arti dan bermanfaat bagi seseorang yang membutuhkan (Wilkinson, 2000: 5).

Agar bermanfaat dalam pengambilan keputusan dan berkualitas, maka informasi harus bernilai, yang berarti mempunyai kualifikasi sebagai berikut: akurat, tepat waktu, waktu tanggap, kelengkapan, relevan. Akurat berarti informasi harus cermat dan bebas dari kesalahan, tepat waktu berarti informasi harus tersedia pada saat dibutuhkan, kelengkapan berarti informasi harus dapat melaporkan kondisi yang sebenarnya dan tidak ada yang dirahasiakan, relevan berarti informasi bermanfaat bagi pemakai untuk dapat digunakan sebagai pengambil keputusan. Di antara beberapa pemakai informasi tersebut, ada pihak eksternal dan pihak internal. Pihak internal ada manajemen dan karyawan, dan pihak eksternal terdapat investor, kreditor, dan pihak lainnya yang berada di luar perusahaan.
\end{abstract}

Kata Kunci : eksternal terdapat investor,kreditor,dan pihak lain 


\section{A . PENDAHULUAN}

Audit Sumber Daya Manusia (SDM) merupakan bagian dari audit manajemen.Audit SDM merupakan penilaian dan analisis yang komprehensif terhadap program-program SDM. Audit manajemen sumber daya manusia dapat 7dilakukan pada fungsi-fungsi operasional dari manajemen sumber daya manusia seperti perencanaan tenaga kerja, rekrutmen, seleksi, orientasi dan penempatan serta pelatihan dan pengembangan. Audit manajemen sumber daya manusia berfokus kepada pencarian data dan informasi permasalahan perusahaan dari perspektif sumber daya manusia, lebih spesifik menyangkut masalah-masalah yang dapat menyebabkan kegagalan perusahaan serta memberikan rekomendasi perbaikan atas berbagai kekurangan yang terjadi pada aktivitas sumber daya manusia yang diaudit.

Menurut Winoto (2010) perhatian terhadap audit sumber daya manusia belum

banyak dilakukan, padahal sebagai salah satu aset terpenting dalam perusahaan, sumber daya manusia haruslah dapat dikembangkan semaksimal mungkin.

Pengelolaan sumber daya manusia pada suatu perusahaan menjadi tanggung jawab

dari Human Resource Development (HRD) atau bagian sumber daya manusia.

Pengelolaan sumber daya manusia dilaksanakan menurut kebijakan suatu perusahaan

mengenai bidang sumber daya manusia yang telah ditetapkan.

Audit manajemen sumber daya manusia diperlukan untuk meningkatkan

kinerja karyawan dalam perusahaan. Peningkatan kinerja karyawan dapat dianggap

sebagai suatu keberhasilan perusahaan. Salah satu faktor yang menyebabkan meningkatnya kinerja karyawan adalah proses dari pelaksanaan sasaran audit manajemen sumber daya manusia. Proses pelaksanaan sasaran audit manajemen

sumber daya manusia jika dilaksanakan dengan tepat, maka perusahaan dapat mengembangkan dan mengevaluasi karyawan sesuai dengan kualifikasi yang

ditentukan perusahaan guna mencapai tujuannya. Menurut Siagian (2004:75) ada

8lima sasaran dari audit manajemen sumber daya manusia yaitu perencanaan tenaga

kerja, rekrutmen, seleksi, orientasi dan penempatan, serta pelatihan dan pengembangan.

\section{B . PEMBAHASAN / STUDI KASUS}

Berkaitan dengan perkembangan teknologi informasi dengan pemakaian jaringan komputer yang semakin luas, maka proses transaksi juga mengalami perubahan, proses transaksi diharapkan semakin cepat, dan semakin luas. Dengan demikian proses akuntansi juga akan mengalami perubahan, karena semakin meningkatnya kebutuhan informasi yang cepat, luas dan akurat, maka akuntansi sebagai suatu proses yang akan menghasilkan informasi keuangan juga mengalami perkembangan. Hal ini merupakan kecenderungan perkembangan akuntansi di saat ini dan masa mendatang. Dalam kondisi teknologi informasi yang berkembang seperti sekarang ini, akuntan dituntut untuk dapat mengikuti perkembangan tersebut dengan berusaha untuk mempelajari teknologi informasi. Ada beberapa alasan mengenai pentingnya akuntan mempelajari teknologi informasi tersebut, diantaranya akuntan diharapkan tidak hanya sebagai pengguna tetapi 
diharapkan sebagai pengembang suatu sistem dan sebagai auditor diharapkan dapat mengevaluasi suatu sistem, dengan memiliki kemampuan tersebut maka akuntan dapat memperoleh posisi yang menguntungkan seiring dengan perkembangan sistem informasi seperti sekarang ini (Wilkinson, 2000:4).

\section{C . ID SECURITY}

QWTD4452377-ASP-5244166

\section{D . KESIMPULAN}

Kesimpulan dari materi ini adalah Audit Sistem Informasi sebuah proses yang sistematis dalam mengumpulkan dan mengevaluasi bukti-bukti untuk menentukan bahwa sebuah sistem informasi berbasis komputer yang digunakan oleh organisasi telah dapat mencapai tujuannya.

Audit merupakan sebuah kegiatan yang melakukan pemerikasaan untuk menilai dan mengevaluasi sebuah aktivitas atau objek seperti implementasi pengendalian internal pada sistem informasi akuntansi yang pekerjaannya ditentukan oleh manajemen atau proses fungsi akuntansi yang membutuhkan improvement. Sehingga dapat bermanfaat bagi perusahaan yang ada di dalam nya.

\section{E . DISKUSI}

Saya bersama teman saya bernama Rudi mendiskusikan tentang contoh ini dengan sangat baik Hasil diskusi dari materi ini adalah menerangkan tentang audit Perkembangan pelaksanaan Audit di Era teknologi informasi Bali sehingga semoga dapat bermanfaat bagi penulis dab pembaca.

\section{F . REFERENCE}

[1] O. M. Febriani and A. S. Putra, "Sistem Informasi Monitoring Inventori Barang Pada Balai Riset Standardisasi Industri Bandar Lampung," J. Inform., vol. 13, no. 1, pp. 90-98, 2014.

[2] A. S. Putra, "Paperplain: Execution Fundamental Create Application With Borland Delphi 7.0 University Of Mitra Indonesia," 2018.

[3] A. S. Putra, "2018 Artikel Struktur Data, Audit Dan Jaringan Komputer," 2018.

[4] A. S. Putra, "ALIAS MANAGER USED IN DATABASE DESKTOP STUDI CASE DB DEMOS."

[5] A. S. Putra, "COMPREHENSIVE SET OF PROFESSIONAL FOR DISTRIBUTE COMPUTING."

[6] A. S. Putra, "DATA ORIENTED RECOGNITION IN BORLAND DELPHI 7.0."

[7] A. S. Putra, "EMBARCADERO DELPHI XE 2 IN GPU-POWERED FIREMONKEY APPLICATION."

[8] A. S. Putra, "HAK ATAS KEKAYAAN INTELEKTUAL DALAM DUNIA TEKNOLOGY BERBASIS REVOLUSI INDUSTRI 4.0."

[9] A. S. Putra, "IMPLEMENTASI PERATURAN PERUNDANGAN UU. NO 31 TAHUN 2000 TENTANG DESAIN INDUSTRI BERBASIS INFORMATION TECHNOLOGY."

[10] A. S. Putra, "IMPLEMENTATION OF PARADOX DBASE."

[11] A. S. Putra, "IMPLEMENTATION OF TRADE SECRET CASE STUDY SAMSUNG MOBILE PHONE."

[12] A. S. Putra, "IMPLEMENTATION 
PATENT FOR APPLICATION WEB BASED CASE STUDI WWW. PUBLIKLAMPUNG. COM."

[13] A. S. Putra, "IMPLEMENTATION SYSTEM FIRST TO INVENT IN DIGITALLY INDUSTRY."

[14] A. S. Putra, "MANUAL REPORT \&

INTEGRATED

DEVELOPMENT

ENVIRONMENT BORLAND

DELPHI 7.0."

[15] A. S. Putra, "PATENT AS RELEVAN SUPPORT RESEARCH."

[16] A. S. Putra, "PATENT FOR RESEARCH STUDY CASE OF APPLE. Inc."

[17] A. S. Putra, "PATENT PROTECTION FOR APPLICATION INVENT."

[18] A. S. Putra, "QUICK REPORT IN PROPERTY PROGRAMMING."

[19] A. S. Putra, "REVIEW CIRCUIT LAYOUT COMPONENT REQUIREMENT ON ASUS NOTEBOOK."

[20] A. S. Putra, "REVIEW TRADEMARK PATENT FOR INDUSTRIAL TECHNOLOGY BASED 4.0."

[21] A. S. Putra, "TOOLBAR COMPONENT PALLETTE IN OBJECT ORIENTED PROGRAMMING."

[22] A. S. Putra, "WORKING DIRECTORY SET FOR PARADOX 7."

[23] A. S. Putra, "ZQUERY CONNECTION IMPLEMENTED PROGRAMMING STUDI CASE PT. BANK BCA Tbk."

[24] A. S. Putra, D. R. Aryanti, and I. Hartati, "Metode SAW (Simple Additive Weighting) sebagai Sistem Pendukung Keputusan Guru Berprestasi (Studi Kasus: SMK Global Surya)," in Prosiding
Seminar Nasional Darmajaya, 2018, vol. 1, no. 1, pp. 85-97.

[25] A. S. Putra and O. M. Febriani, "Knowledge Management Online Application in PDAM Lampung Province," in Prosiding International conference on Information Technology and Business (ICITB), 2018, pp. 181187.

[26] A. S. Putra, O. M. Febriani, and B. Bachry, "Implementasi Genetic Fuzzy System Untuk Mengidentifikasi Hasil Curian Kendaraan Bermotor Di Polda Lampung," SIMADA (Jurnal Sist. Inf. dan Manaj. Basis Data), vol. 1, no. 1, pp. 21-30, 2018.

[27] A. S. Putra, H. Sukri, and K. Zuhri, "Sistem Monitoring Realtime Jaringan Irigasi Desa (JIDES) Dengan Konsep Jaringan Sensor Nirkabel," IJEIS (Indonesian J. Electron. Instrum. Syst., vol. 8, no. 2, pp. 221-232.

[28] D. P. Sari, O. M. Febriani, and A. S. Putra, "Perancangan Sistem Informasi SDM Berprestasi pada SD Global Surya," in Prosiding Seminar Nasional Darmajaya, 2018, vol. 1, no. 1, pp. 289-294. 